\title{
Juxtaposing Transduction and Transtraction: Pugging in International Virtual Teams
}

\section{Tobias M. Scholz ${ }^{1}$ Volker Stein ${ }^{2}$}

Recibido: 2017-03-31

Enviado a pares: 2017-03-31
Aprobado por pares: 2017-04-11

Aceptado: 2017-04-12

DOI: $10.5294 /$ pacla.2017.20.3.9

Para citar este artículo / to reference this article / para citar este artigo

Scholz, T.M. y Stein, V. (2017). Juxtaposing transduction and transtraction: Pugging in international virtual teams. Palabra Clave, 20(3), 788-804. DOI: 10.5294/pacla.2017.20.3.9

\section{Abstract}

Despite the recent surge in digitization, organizations still struggle with utilizing international virtual teams. Such teams still tend to follow the concept of top-down planning and are, therefore, controlled by some sort of headquarter. In the context of multiplayer games, however, we observe a more self-organized way of establishing teams, which is commonly referred to as pugging: Teams emerge, establish a shared goal, and disband afterwards. They follow the concept of bottom-up autonomy. Pugging is highly beneficial to the gaming world, which is why we will follow the cultural transduction framework to transfer this team concept from gaming to the corporate context. Since the corporate context and gaming are strongly intertwined and influence one another to a great extent, we will expand this framework with the concept of transtraction.

\section{Keywords}

International virtual teams; pugging; transduction; transtraction (Source: Unesco Thesaurus).

1 orcid.org/0000-0001-5314-0814. University of Siegen. Alemania. tobias.scholz@uni-siegen.de

2 University of Siegen. Alemania. volker.stein@uni-siegen.de 


\section{Yuxtaposición, transducción y transtracción: pugging en equipos virtuales internacionales}

\section{Resumen}

A pesar del reciente auge de la digitalización, las organizaciones todavía tienen dificultades con el uso de equipos virtuales internacionales, que aún tienden a seguir el concepto de planificación top-down (de arriba abajo) y, por consiguiente, son controladas por algún tipo de sede. Sin embargo, en el contexto de los juegos de multijugadores, observamos una manera más auto-organizada de formar equipos, lo que comúnmente se conoce como pugging: se forman los equipos, se establece un objetivo común y luego se disuelven. Siguen el concepto de autonomía ascendente. El pugging es altamente beneficioso para el mundo del juego, razón por la cual seguiremos el marco de la transducción cultural para transferir este concepto de equipo del juego al contexto corporativo. Puesto que el contexto corporativo y el juego están fuertemente entrelazados y se influyen mutuamente en gran medida, expandiremos este marco con el concepto de transtracción.

\section{Palabras clave}

Equipos virtuales internacionales; pugging; transducción; transtracción (Fuente: Tesauro de la Unesco). 


\section{Justaposição, transdução e transtração: pugging em equipes virtuais internacionais}

\section{Resumo}

Apesar do recente auge da digitalização, as empresas têm dificuldades com o uso de equipes virtuais internacionais, que ainda tendem a seguir $o$ conceito de planejamento top-down (de cima para baixo) e, portanto, são controladas por algum tipo de sede. Porém, no contexto dos jogos de multijogador, observamos uma maneira mais auto organizada de formar as equipes, que comumente se conhece como pugging: as equipes se formam, estabelece-se um objetivo comum, e em seguida se dissolvem. Essas equipes seguem o conceito de autonomia ascendente. O pugging é altamente benéfico para o mundo do jogo, razão pela qual seguiremos o contexto de transdução cultural para transferir este conceito de equipe de jogo para o contexto corporativo. Como o contexto empresarial e os jogos estão fortemente interligados e se influenciam mutuamente, expandiremos essa estrutura com o conceito de transtração.

\section{Palavras-chave}

Equipes virtuais internacionais; pugging; transdução; transtração (Fonte: Tesauro da Unesco). 


\section{Introduction}

Recent technological progress has enabled us to communicate and collaborate with people from around the world in real-time. Tools like video-conferencing drastically transform the way we work. Without the shackles of space, global collaboration has become achievable for anyone. While the number of international virtual teams is increasing, organizations still struggle with the utilization of those teams. Even though international teams are no longer an unusual sight in organizations, there is still great potential for improvement when it comes to truly exploiting digitization (Marlow, Lacerenza, \& Salas, 2017). In particular, new technologies such as augmented reality, in theory, allow for physical interactions between members of a virtual team. It is, therefore, essential to understand that the definition of international virtual teams changes with the technological progress, even though this does not seem to be the case at the moment (Stein, 2015).

International virtual teams focus on the corporate context and, therefore, only consider one dimension of digitization. Consequently, the process of virtualization may be more advanced in other areas affected by digitization. Researching those different approaches towards teams and comparing them to teams in the corporate context may, therefore, be the reasonable next step. Is it possible to derive potential improvements for international virtual teams? This resembles the concept of cultural transduction (Uribe-Jongbloed \& Espinosa-Medina, 2014), which refers to a product or idea that has moved beyond its original environment to other environments. In the course of this paper, we will research the digitization process of video games and the way in which teams evolve over time. The concept of pickup groups (PUGs) or the process of pugging seem especially striking. Even though collaboration is limited to a short period of time for those teams, they are virtually constructed, which is why many of them classify as international virtual teams. This shows that the logic of transduction can be applied. We assume that, in this case, the process of transduction may be more emergent and less one-directional than originally theorized. On this notion, we will expand the transduction concept with the idea of transtraction, thereby grasping the ongoing exchange and interconnection present in the digital world. 


\section{The Phenomenon}

\section{Changing narration of international virtual teams}

The research on international virtual teams started in the early 1990s and is linked to the growth of the Internet. Consequently, organizing virtual team structures posed one major obstacle (e.g., Davidow \& Malone, 1992; Venkatraman \& Henderson 1998). One popular definition of international virtual teams at the time was the following:

An evolutionary form of a network organization enabled by advances in information and communication technology. The concept virtual implies permeable interfaces and boundaries; project teams that rapidly form, reorganize, and dissolve when the needs of a dynamic marketplace change; and individuals with differing competencies who are located across time, space, and cultures. (Jarvenpaa \& Leidner, 1999, p. 791)

This definition highlights the prevalent and still dominant understanding of international virtual teams as highly embedded within the corporate context and structures. Nevertheless, the definition implies a more emergent tendency, as well as open and emergent structures in international virtual teams. These teams, however, tend to strictly be structured in a topdown manner. They solve the problem of cross-cultural cooperation within a corporation (Van Ryssen \& Godar, 2000). The headquarter formally sets up and centrally plans those international virtual teams. This leads to an increase in complexity, requires resources, and undermines the idea of decentralization associated with such international virtual teams. International virtual teams are embedded within the organization and do not have the required freedom to self-organize or even self-allocate.

In the face of digitization, this perspective is outdated. It was already so in 2006, when Bergiel et al. described that, in today's market, global virtual teams are not the exception but the rule as companies expand into the global market. International virtual teams are necessary, but those teams rely on a bottom-up autonomy. In order to harness the potential of international virtual teams, they depend on the autonomy from a central head- 
quarter and the freedom of self-coordination. Consequently, the narration of international virtual teams has shifted from top-down planning to bottom-up autonomy.

International virtual teams are, therefore, "the result of self-directed, autonomous and spontaneous interaction of internationally distributed team members who informally converge around joint interests and stay together as long as they benefit from mutually reciprocal behavior. The emerging robustness of the higher-order corporate system is a desirable side benefit" (Stein, 2015, p. 7).

\section{Deconstructing Pugging}

Reviewing the interactions and processes in the digital sphere, we observe that teams outside of the corporate context sometimes act truly self-directed and autonomous. People spontaneously form teams that then disband after a short period of time. They follow the idea of bottom-up autonomy. Furthermore, there is no entity that directly gives instructions and manages these teams in detail. Nevertheless, the environment in which these teams interact is determined. For that reason, this self-organized behavior can often be observed in video games or, more precisely, in players of multiplayer games like League of Legends or World of Warcraft.

A noticeable factor is the popularity of those games. In 2014, nearly 27 million people played at least one game per day (Riot, 2014). The game World of Warcraft had about 10 million subscribers in 2016 (Kollar, 2016). Newer games such as Overwatch have over 25 million players (Statt, 2017). Even though these are only three examples, the numbers speak for themselves. Multiplayer games are no longer a niche product, but have legitimately become part of people's everyday life. Taking into consideration that the average player is around 30 years old (Grubb, 2014), their behavior in the game can be assumed to have an influence on their behavior at work and vice versa. Consequently, a form of cultural transduction is happening.

The obvious influence is that of work behavior on that in multiplayer games. Players form a group for a longer period of time to achieve a 
certain pre-defined long-term goal (Nardi \& Harris, 2006). These groups are similar to a formal organization and exhibit a distinct top-down hierarchy (Rezvani, 2008). There are leaders, there are people with specialized roles, and there is a sizable set of rules. These constructs are often referred to as clans, guilds, or corporations. The last type already reveal the connection to the business context. These groups mimic the real world and translate it into the game environment. Players gather on the basis of a shared perception of the game world. There are groups that resemble a military organization with its stringent hierarchy and strict rules, as well as groups that try to be more flexible or dynamic, much like a start-up organization. However, all of them are founded on the basis of a long-term commitment of the players.

Beside these clans or guilds, there are other forms of groups. These other forms of groups are co-existent to, and do not stand in competition with the formal organization in clans or guilds. They are, however, temporally limited. These temporary teams are often described as "pickup groups", and the process is called pugging (Kou \& Gui, 2014). Players have the freedom to do everything they want within the game and can quickly form and disband groups. Consequently, these teams are assembled for a singular purpose, e.g., beating a difficult boss. Once their goal has been achieved, these teams disband. There is no extensive commitment but a high short-term goal orientation (Bardzell, Bardzell, Pace \& Reed, 2008). Pickup groups focus on the self-determination of players and their willingness to spend time as part of a group in order to achieve their own goal. The game environment allows for the players to find each other. This is only the infrastructure, however. The game itself poses certain rules itself, which narrows the selection process a bit. A group in World of Warcraft, for example, requires tanks, healers, and damage dealers. But the player can open up a group and search for similar-minded people, which makes pickup groups a bottom-up phenomenon in the purest sense. Interestingly, these groups form beyond national borders and players from all around the world or at least from the same continent (due to technological barriers) are capable of pugging in order to achieve their shared goals. 
Pickup groups represent a very unique form of groups that sets itself apart from the division into clans, guilds, virtual corporations, and real world corporations. Pugging enforces temporary relationships. People group up for a short period of time and go their own ways afterwards. This generates highly dynamic groups. Without a predefined set of rules from a formal organization, structures within the group are predominately informal and emerge over time. Furthermore, these groups exhibit a high level of heterogeneity. The only common ground is the shared goal that leads to a highly diverse group. This may also create fragile relationships, especially as there are no formal penalties for leaving the group.

Individual behaviors within such pickup groups differ greatly, especially due to the short-term orientation of pugging. Consequently, their behavior as groups differs from that of formal organizations as well. First of all, these teams are highly volatile and fast paced. Therefore, communication needs to be as precise as possible. This does not, however, point to the existence of language barriers. Although there are different cultures within each group, members share a mutual game culture (Shaw, 2010), which brings along its own vocabulary (Poels, Ijsselsteijn \& de Kort, 2015). Players are capable of communicating using a set of trigger words which renders their language very precise and enables them to efficiently establish a common goal (Leavitt, Keegan \& Clark, 2016). The chances of achieving said goal are constantly evaluated by the players. In order to keep the group together, strategic moves are essential to achieve quick wins, thus further strengthening the temporary bond. Without a predefined leadership, some form of leadership naturally emerges. This leads to an understanding of pugging that is vastly different from the top-down autonomy known from corporations. The level of self-determination in pickup groups is high, but requires self-discipline. People invest resources and time into the group and, although it is easy to leave the group, players continuously weigh up their chance of winning against the risk of "wasting time." For that reason, the role of the individual is critical and the team's success depends on the proactivity of every member of the group. Without predefined leadership and rules, they have to produce ideas and are required to deliver top performance. People seemingly are more willing to trust emerging 
leaders, but are also more likely lose their trust (and leave the group). Killing the morale happens more easily when pugging than it does in formal organizations (Kou \& Gui, 2014).

Formal and informal organizations co-exist within the game environment; they even balance out the game world. A formal organization gives the player structure, and comradery, it and enables long-term commitment. It provides order and a sense of community. Self-determination, however, subordinates to the rules of the clan or guild. In many cases, pugging provides a solution on the other side of the spectrum. It focuses strongly on self-determination and makes the game world more dynamic. It enforces variation and heterogeneity and, therefore, renders the gaming world more chaotic. It makes the gaming world livelier and increases the activity level of the players. Both types coexist and thrive on each other. They are not mutually exclusive; they complement each other and, in the end, create a more balanced gaming world.

\section{Applying the Logic of Cultural Transduction}

The concept of cultural transduction was researched originally in the audiovisual context and observes the flow of cultural phenomena from one cultural context to another (Uribe-Jongbloed, \& Espinosa-Medina, 2014). It strongly focuses on the idea of national or regional cultures. It seems possible and necessary, however, to understand culture in a broader sense. Uribe-Jongbloed, Espinosa-Medina and Biddle (2016) utilized the concept of cultural transduction in the context of video games and revealed that video games succumb to the cultural transduction framework, albeit, still in the setting of national cultures. This paper goes beyond national culture and understands culture as a description of behavior in a certain context. People tend to follow a certain type of cultural behavior depending on their environment and, therefore, in the context of video games, this cultural behavior can be referred to as game culture (Shaw, 2010). Furthermore, international virtual teams tend to follow a corporate culture, especially as they are still dominated by top-down planning. We propose that the cultural transduction framework can transfer the knowledge and concepts from the game culture to the corporate culture within an organization. 
Uribe-Jongbloed and Espinosa-Medina divide the cultural transduction framework into markets, process, people, and product. The division place was added recently (Uribe-Jongbloed et al., 2016). In the following paragraphs, we will apply the logic of cultural transduction to pugging and the transfer to international virtual teams in the context of cooperation.

First of all, markets are categorized into cultural proximity, cross-cultural predictability, and cultural entrance barriers. As described earlier, game culture and work environment exhibit a certain cultural proximity due to the fact that both cultures are shared with the same group of people. Players work and workers play. The overlap has dramatically increased in recent years (Oprescu, Jones, \& Katsikitis, 2014) and it is quite common for people in a corporation to frequently play games. The shared pool of people leads to the great cultural proximity of work and play. Cross-cultural predictability, however, is low due to the reason that the opinion of no actual linkage between games and work is still predominant. Although Dewey has already propagated a link between play and work in 1916, the understanding of Huizinga's (1949), who claims that there is no connection between play and work, is prevailing. He states that play is always a voluntary activity. Recent advancements in gamification (Stein \& Scholz, 2016) and playbour (Kücklich, 2005), however, show that play and work are somehow cross-culturally linked. Consequently, the effects of a game culture on the corporation becomes increasingly predictable and observable. The impact of pugging on international virtual teams is still questionable. Although, as stated earlier, the narration of international virtual teams is changing, the shift from top-down planning to bottom-up autonomy is radical and history reveals a certain inability of adaptation within the understanding of international virtual teams.

Secondly, the process of pugging allows for an interesting observation. Generally speaking, due to self-autonomy, emerging structure and flexibility, the process can easily be translated to fit any corporation. There is no need for translation or transmediation. Adaptability is a cornerstone of pugging so, in theory, the concept of pugging will adapt to the different environment that is a corporation. The strength of pugging is its ability to 
adapt to any new environment. Every new pickup group is a clean slate. The process evolves over time and every pickup group is unique in its own process. Patterns may evolve. Any deliberate utilization of patterns, however, would weaken the bottom-up autonomy of pugging.

Thirdly, people are critical in the cultural transduction process. The way in which people would implement the concept of pugging depends on the respective corporate culture. Especially the way in which people communicate is bound to greatly impact cultural transduction. The framework categorizes people into scouts, merchants, and alchemists. Scouts and merchants are not that relevant for this particular case, as they seek and acquire new products or concepts. Alchemists are more important for this cultural transduction. They act as gatekeepers (Conway, 2012) and translate from the original context into an appropriate context within the new environment: in this case, from pugging in the game culture to international virtual teams in the corporate context. Communication may differ from corporation to corporation, but remains crucial for cultural transduction. There is a spectrum of potential ways. On the one hand, the alchemist could talk about the game culture in depth and flag it as some form of gamification or, on the other hand, eliminate any game wording from the transfer process. Pugging can be described with game lingua or completely without game terminology. The question for the alchemist is: Which way is more promising?

Fourth division is the product that already co-aligns with the process and the work of the alchemist. There is a certain universality of the product pugging that makes it possible to remove its cultural lacunae (Rohn, 2011). While there may be a space between the game culture and the people within a corporation and the potential international virtual teams, pugging does not require the terminology of gaming in order to work, but may act as a potential enforcer or driver for the transfer. Furthermore, pugging depends on transparency. Pickup groups are built on transparency. Without it, they will disband immediately. They also require shareability, as the sharing process enables pugging to find potential group members in the first place. 
Finally, the division of place elaborates the aspects of hybridity and convergence. This seems to be the most difficult aspect of cultural transduction, especially as it describes a spectrum of two opposites. Therefore, the comparison to discourse about convergence and divergence seems obvious. Nevertheless, the concept of pugging strongly emphasizes co-existence. Especially as pugging focuses on the concepts of self-organization and emergence, there is no necessity to consider the potential forces of convergence and divergence. More relevant, however, is the observation of the gravitational effects in the organization. This form of informal organization will have an impact on the formal organization. The formal organization, however, will influence the informal organization as well. Pugging on international virtual teams will change the organization, but whether this will lead to convergence or divergence remains unclear.

In summary, the markets of game culture and corporation are quite similar and will converge in the future. The process of pugging is, in a certain sense, cultureless and, by definition, highly adaptable. Furthermore, the product enables the people (especially the alchemist) to find a suitable way of communicating pugging in international virtual teams. Even though the place of pugging may not fit either hybridity or convergence, it is in a constant state of concurrence. Nevertheless, the concept of pugging can be transferred conveniently form the game culture to the corporation.

\section{Beyond Transduction: Applying the Logic of Transtraction}

One aspect that is relevant for this example of cultural transduction is that pugging is already a form of international virtual teams, even though pugging does not take place to quite the same extent in the context of corporations. The freedom to participate and cooperate is strongly rooted in the gamer culture (Shaw, 2010), as well as in hacker culture (Scholz \& Reichstein, 2015). For that reason, it is observable that the amount of people demanding the freedom to form temporary teams will increase as the impact of the gamer culture and hacker culture keeps growing. However, pugging goes beyond cultural transduction as described by Uribe-Jongbloed 
and Espinosa-Medina (2014), especially as international virtual teams, in theory, are already bottom-up, self-organized, autonomous teams. Pugging is an example of this development, and a seemingly successful one. Therefore, we assume that a transtraction logic can be observed in the effect of pugging on international virtual teams.

At the moment, international virtual teams are still rooted in the concept of top-down planning, although the positive sides of bottom-up autonomy are already known. Pugging can act as a gravitational force to encourage organizations to give their employees the freedom to form pickup groups autonomously. The benefit of this lies in an increase in diversity, variation and, to a certain degree, in the democratization of the organization. This may boost creativity and, consequently, generate additional innovative potential in the organization. Similar to video games, however, a shift from formal organization to informal organization will not take place. Since both aspects have a gravitational force, a transtraction will be observable. Bottom-up autonomy in temporary teams tends to be chaotic. Top-down planning, on the other hand, focuses on order. Both extremes in isolation are not beneficial for the organization. At the moment, however, transtraction in corporations is dominated by top-down planning. Introducing the capability of pugging into an organization pushes the corporation away from strict order, convergence, and homogeneity, and towards chaos, divergence, and heterogeneity.

Consequently, the emphasis lies on the co-existence of formality and informality, of long-term and short-term, and of order and chaos. This is the critical aspect, in which the case goes beyond cultural transduction and the transfer from one context to another. Pugging may have emerged in the game context, but it is not exclusively a phenomenon found in video games. Pugging is a form of international virtual teams. Pugging stirs up the current understanding of international virtual teams. It is the required counter-pole for the formal organization of international virtual teams as it exists today. The resulting transtraction will render the organization more flexible and dynamic, while at the same time keeping it more balanced and stable. 


\section{References}

Bardzell, S., Bardzell, J., Pace, T. \& Reed, K. (2008). Blissfully productive: Grouping and cooperation in World of Warcraft instance runs. Proceedings of the 2008 ACM Conference on Computer Supported Cooperative Work (pp. 357-360).

Bergiel, B. J., Bergiel, E. B. \& Balsmeier, P. W. (2006). The reality of virtual teams. Competition Forum, 4(2), 427-432.

Conway, K. (2012). Cultural translation, global television studies, and the circulation of telenovelas in the United States. International Journal of Cultural Studies, 15(6), 583-598.

Davidow, W. H. \& Malone, M. S. (1992). The virtual corporation. Structuring and revitalising the corporation for the 21st century. New York: Harper.

Dewey, J. (1916). Democracy and education. An introduction to the philosophy of education. New York: Macmillan.

Grubb, J. (2014). Gaming advocacy group: The average gamer is 31, and most play on a console. Retrieved from https://venturebeat. com/2014/04/29/gaming-advocacy-group-the-average-gameris-31-and-most-play-on-a-console.

Huizinga, J. (1949). Homo ludens. A study of the play-element in culture. London: Routledge.

Jarvenpaa, S. L. \& Leidner, D. E. (1999). Communication and trust in global virtual teams. Organization Science, 10(6), 791-815.

Kollar, P. (2016). Did Legion boost World of Warcraft's subscriber numbers over 10 million? Retrieved from http://www.polygon. 
com/2016/10/4/13167592/world-of-warcraft-legion-subscriber-numbers-10-million

Kou, Y. \& Gui, X. (2014). Playing with strangers: Understanding temporary teams in League of Legends. Proceedings of the First ACM SIGCHI Annual Symposium on Computer-Human Interaction in Play (pp. 161-169).

Kücklich, J. (2005). Precarious playbour: Modders and the digital games industry. Fibreculture, 3. Retrieved from http://five.fibreculturejournal.org/fcj-025-precarious-playbour-modders-and-the-digital-games-industry

Leavitt, A., Keegan, B. C. \& Clark, J. (2016). Ping to win?: Non-verbal communication and team performance in competitive online multiplayer games. Proceedings of the 2016 CHI Conference on Human Factors in Computing Systems (pp. 4337-4350).

Marlow, S. L., Lacerenza, C. N. \& Salas, E. (2017). Communication in virtual teams: A conceptual framework and research agenda. Human Resource Management Review, forthcoming.

Nardi, B. \& Harris, J. (2006). Strangers and friends: Collaborative play in World of Warcraft. Proceedings of the 2006 20th Anniversary Conference on Computer Supported Cooperative Work (pp. 149-158).

Oprescu, F., Jones, C. \& Katsikitis, M. (2014). I play at work - ten principles for transforming work processes through gamification. Frontiers in Psychology, 5, 1-5.

Poels, K., Ijsselsteijn, W. A. \& de Kort, Y. (2015). World of Warcraft, the aftermath: How game elements transfer into perceptions, associations and (day) dreams in the everyday life of massively multiplayer online role-playing game players. New Media \& Society, 17(7), 1137-1153. 
Rezvani, J. (2008). Guild leadership. Morrisville: Lulu.

Riot Games. (2014, January 28). League players reach new heights in 2014. Retrieved from http://www.riotgames.com/articles/20140711/1322/league-players-reach-new-heights-2014.

Rohn, U. (2011). Lacuna or universal? Introducing a new model for understanding cross-cultural audience demand. Media, Culture \& Society, 33(4), 631-641.

Scholz, T. M. \& Reichstein, M. S. (2015). Wenn neue Paradigmen in die Gestaltung von Arbeitswelten eingreifen: Hacker-Ethos in der Digitalisierung. In S. Habscheid, G. Hoch, H. Schröteler-von Brandt, \& V. Stein (Eds.), Zum Thema: Gestalten gestalten. Diagonal Heft 36 (pp. 135-148). Göttingen: Vandenhoeck \& Ruprecht.

Shaw, A. (2010). What is video game culture? Cultural studies and game studies. Games and Culture, 5(4), 403-424.

Statt, N. (2017). Overwatch now has more than 25 million registered players. Retrieved from http://www.theverge.com/2017/1/26/14407332/ overwatch-blizzard-25-million-players

Stein, V. (2015). Revisiting international virtual teams: The role of intercultural competence. Proceedings of the EGOS: Sub-Theme No 66 "When Reason is not Enough: Intercultural Competence Acquisition and Use. Athens, Greece.

Stein, V. \& Scholz, T. M. (2016). Making dynamics work: The strategic potential of gamification for human resource management. Proceedings of the $2^{\text {nd }}$ Academy of Management HR Division International Conference (pp. 1-27). Sydney, Australia.

Uribe-Jongbloed, E. \& Espinosa-Medina, H. D. (2014). A clearer picture: Towards a new framework for the study of cultural transduction in audiovisual market trades. Observatorio $\left(O B S^{*}\right), 8(1), 23-48$. 
Uribe-Jongbloed, E., Espinosa-Medina, H. D., \& Biddle, J. (2016). Cultural transduction and intertextuality in video games: An analysis of three. In C. Duret, \& C.-M. Pons (Eds.), Contemporary research on intertextuality in video games (pp. 143-161). Hershey, PA: IGI Global.

Van Ryssen, S. \& Godar, S. H. (2000). Going international without going international: multinational virtual teams. Journal of International Management, 6(1), 49-60.

Venkatraman, N. \& Henderson, J. C. (1998). Real strategies for virtual organizing. Sloan Management Review, 40(1), 33-48. 